\title{
Spring migration duration exceeds that of autumn migration in Far East Asian Greater White-fronted Geese (Anser albifrons)
}

\author{
Xueqin Deng ${ }^{1,2 \dagger}{ }^{\dagger}$ Qingshan Zhao ${ }^{1 \dagger}$, Lei Fang ${ }^{3}$, Zhenggang Xu ${ }^{4}$, Xin Wang ${ }^{1}$, Haoren He ${ }^{5}$, Lei Cao ${ }^{1,2^{*}}$ \\ and Anthony David Fox ${ }^{6}$
}

\begin{abstract}
Background: Migration theory suggests, and some empirical studies show, that in order to compete for the best breeding sites and increase reproductive success, long-distance avian migrants tend to adopt a time minimization strategy during spring migration, resulting in shorter duration spring migration compared to that in autumn.

Methods: Using GPS/GSM transmitters, we tracked the full migrations of 11 Greater White-fronted Geese (Anser albifrons) between southeast China and the Russian Arctic, to reveal the migration timing and routes of the East Asian population, and compare the difference in duration between spring and autumn migration of this population.

Results: We found that migration in spring ( $79 \pm 12$ days) took more than twice as long to cover the same distance as in autumn ( $35 \pm 7$ days). This difference in migration duration was mainly determined by significantly more time spent in spring ( $59 \pm 16$ days) than in autumn ( $23 \pm 6$ days) at significantly more stopover sites.

Conclusions: We suggest that these geese, thought to be partial capital breeders, spent almost three quarters of total migration time at spring stopover sites to acquire energy stores for ultimate investment in reproduction, although we cannot reject the hypothesis that timing of the spring thaw also contributed to stopover duration. In autumn, they acquired necessary energy stores on the breeding grounds sufficient to reach Northeast China staging areas almost without stop, which reduced stopover times in autumn and resulted in the faster autumn migration than spring.
\end{abstract}

Keywords: Greater White-fronted Goose, GPS/GSM tracking, Migration, Spring staging, Stopover duration

\section{Background}

Migration theory predicts that long-distance migrants should minimize the duration of spring migration to ensure early arrival in breeding areas, in an attempt to enhance fitness by occupation of better quality territories (Kokko 1999) and earlier nesting (Moore et al. 2005). Earlier nesting contributes to increased clutch size (Rowe et al. 1994) and fledging of better quality offspring, which better survive their first migration (Perrins 1970;

\footnotetext{
*Correspondence: leicao@rcees.ac.cn

${ }^{\dagger}$ Xueqin Deng and Qingshan Zhao: Shared first authors

${ }^{1}$ State Key Laboratory of Urban and Regional Ecology, Research Center for Eco-Environmental Sciences, Chinese Academy of Sciences, Beijing 100085, China

Full list of author information is available at the end of the article
}

McNamara et al. 1998), as well as providing improved opportunities for females to adjust reproductive investment to maximize fitness (Van Noordwijk et al. 1995). For this reason, spring migration is predicted to be faster than in autumn, when resources are generally more abundant after a summer season of biological productivity, making it less imperative to reach specific goals in time and space. On the other hand, Arctic nesting female geese tend to import energy and nutrients to their nesting area to invest in reproduction in the form of body stores accumulated along the spring flyway (so-called "capital breeding" investment, Drent and Daan 1980). Such endogenous stores are combined to varying degrees with resources garnered locally on arrival near or at the ultimate breeding grounds (e.g. Gauthier et al. 2003; 
Drent et al. 2006). Hence, the quality of, and access to, such sources of exogenous resources to breeding female geese during spring migration will potentially affect their ability to accumulate energy and nutrient stores for ultimate investment in reproduction (e.g. Drent et al. 2006; Hübner et al. 2010) and affect their rate of progress along the flyway in spring.

Most studies of avian migration have revealed that spring migration is faster than autumn migration (Nilsson et al. 2013). Recently, however, studies of long distance $(>2000 \mathrm{~km})$ migratory goose populations have revealed mixed results regarding differences between the duration of spring and autumn migration. Swan Geese (Anser cygnoides) (breeding in the Mongolian steppes and wintering in China) follow the paradigm, undertaking spring migration almost twice as rapidly as they cover the same distance in autumn (Batbayar et al. 2013). Bar-headed Geese (Anser indicus) migrating between Kyrgyzstan and wintering areas in Pakistan, India, and Uzbekistan completed the journeys in more or less the same time (Köppen et al. 2010). Most recently, observations showed that Bewick's Swans (Cygnus columbianus bewickii) migrated slower in spring than in autumn (Nuijten et al. 2014), considered linked to patterns of spring ice thaw. Furthermore, Greater White-fronted Geese (Anser albifrons) migrating between western Europe and the Russian Arctic took almost twice as long to complete spring migration (83 days) than autumn migration (42 days), a difference mainly due to differences in the time spent at stopover sites (Kölzsch et al. 2016).

Greater White-fronted Geese have an almost continuous circumpolar Arctic breeding distribution (Ely et al. 2005), including populations that breed in the Russia Arctic and winter in Japan, Korea and China (Jia et al. 2016). In China, Greater White-fronted Geese mainly overwinter in the Yangtze River Floodplain, where they are reliant upon recessional sedge (Carex spp.) meadows of seasonally inundated lake basins, which are being lost due to hydrological change (Zhao et al. 2012). Unlike Greater White-fronted Geese in North America, Europe, Japan and Korea, which have benefitted from their adaptation to feeding on agricultural subsidies (Fox and Abraham 2017), Chinese birds remain largely confined to natural wetlands in winter (Yu et al. 2017; Zhao et al. 2018). Recent telemetry studies have shown that Chinese wintering Greater White-fronted Geese undertake very long, non-stop autumn migration episodes to clear the taiga forest without refueling (Wang et al. 2018). Most of the main stopover sites on their spring migration are concentrated on the plains of Northeast China, where tracked birds showed some preference for staging on floodplain grasslands, but also croplands, such as maize stubble, that provide rich feeding opportunities now on spring migration (Si et al. 2018). The study of Si et al. (2018) also showed relatively few spring staging stopover points utilized by Greater White-fronted Geese south of $60^{\circ} \mathrm{N}$ after leaving Northeast China. In contrast, NW European Greater White-fronted Geese tended to undertake relative short flights between stopover sites in spring (mean c. $480 \mathrm{~km}$ ) compared to autumn (c. $1280 \mathrm{~km}$, Kölzsch et al. 2016). These differences suggest that circumstances on migration for these Chinese birds may impose different migration patterns on these birds compared to those in western Europe during their $2800-3600 \mathrm{~km}$ migration (Kölzsch et al. 2016). We therefore here test whether the duration of spring migration exceeds that in autumn, as shown in western European Greater White-fronted Geese, equally applied in the Far East Asian flyway, where the species flies $5700-6100 \mathrm{~km}$ from the Yangtze River Floodplain to breed in the Far East Russian Arctic (Wang et al. 2018).

\section{Methods}

\section{Animal capture and GPS-GSM deployment}

We captured 61 Greater White-fronted Geese between October and March on their wintering grounds at Poyang Lake $\left(29^{\circ} 07 \mathrm{~N}, 116^{\circ} 16^{\prime} \mathrm{E}\right)$ and Chenyao Lake (in Anhui lakes, $30^{\circ} 54 \mathrm{~N}, 117^{\circ} 40^{\circ} \mathrm{E}$ ) in the Yangtze River Floodplain, China from 2013 to 2016. Mesmerized geese caught in the beams of powerful lamps were captured in hand nets using boats at night or in heavy-duty mist-nets (designed for catching large birds) set at their roosts. Birds were fitted with a variety of telemetry devices (Druidtech, China 35 g mounted on neckbands, Hunan Global Messenger Technology Company, China, 26 g or $27 \mathrm{~g}$, mounted on neckbands or using back packs) providing GPS positions to within $10 \mathrm{~m}$ accuracy via the GSM mobile telephone networks (Table 1). These devices provided 1 to 48 GPS positions per day, depending on tag capacity and battery conditions (dependent on absorption of solar radiation by the in-built solar panel), but during the active migration periods, almost all the individuals generated hourly diurnal GPS locations during all $24 \mathrm{~h}$ periods.

Some individuals were tracked for more than 1 year, so to avoid pseudo-replication, and only the first spring and autumn migration track were selected from each individual. Device failure, low battery power levels and signal loss hindered the accumulation of precision data, especially in winter when day length was short. We therefore only used tracks from which we obtained 8 to 24 fixes per day along the entire length of the migration routes between breeding and wintering areas. This left tracks of sufficient precision to compile nine complete autumn migration tracks ( 2 in 2015, 5 in 2016, and 2 in 2017) and 11 complete spring migration tracks ( 3 in 2015, 6 in 2016, and 2 in 2017). 


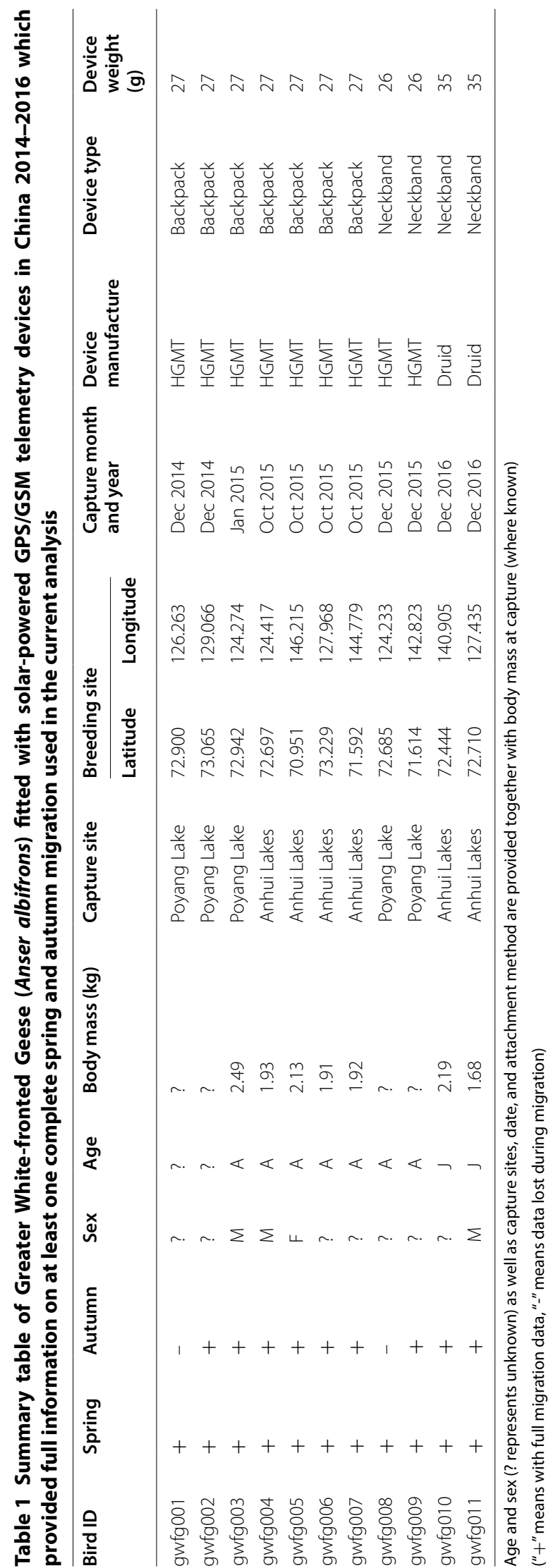


We here consider data from tracks that started from the last location in their wintering areas in China to the first location in their breeding grounds (defined as spring migration), while autumn migration tracks were defined as those starting from the last location on their breeding grounds to the first location in the wintering site.

\section{Data processing and interpretation}

Our telemetry data provided positions of each of the geese sampled at regular intervals through time that constitute the movement tracks between wintering and summering quarters. We calculated great-circle-distances (the "haversine method" (Sinnott 1984) between adjacent GPS locations using the distHavesine function in the geosphere package (Hijmans et al. 2017) in R (R Development Core Team 2017). We followed the method of Kölzsch et al. (2016), Shariatinajafabadi et al. (2014) and van Wijk et al. (2012) to analyse these movements, which briefly involved the following processes (conceptualized in Additional file 1: Figure S1). Our first objective was to objectively differentiate segments of these tracking paths into periods of direct flight movement during migration from segments of relative quiescence (i.e. at stopover/ staging, breeding or wintering areas, when geese will still commute between feeding and roosting areas, but not undertake long directional movement, which constitutes contributions to migration). Following the modified methods of Barraquand and Benhamou (2008) and Le Corre et al. (2014), we segmented tracking paths into periods of direct flight movements and stopovers by using the first passage time (FPT) method (Edelhoff et al. 2016). FPT estimates the time taken from a predefined starting location for each goose to move a given distance away (defined as a circle of given radius around the starting location) by applying the penalized contrast method (Lavielle 2005). The FPT generates the minimum time before a goose crosses a given radius across its path; this value is low when actively flying long distance on migration, high when it remains within a restricted area. The shift between adjacent sequences at breeding, staging and wintering areas (high FPT) and bouts of direct flight movement (true migration, low FPT) identify departure and arrival times/dates during each sequential migration bout. We set the range for optimal FPT radius to be a geometric sequence of 500 steps from 2.5 to $50 \mathrm{~km}$ and applied this as a hierarchical segmentation process with up to 4 iterations for each segment or until no further segmentation was forthcoming (for full details see Wang et al. 2018).

Our second objective was to isolate and identify stopover periods and the sites used, from other periods of a migration episode. We first determined the duration and net squared displacement (NSD, i.e. the minimum distance between locations, Bunnefeld et al. 2011) of segments. If the ratio of the NSD to segment duration was $>150 \mathrm{~km} \mathrm{day}^{-1}$ and NSD $>150 \mathrm{~km}$, or $>75 \mathrm{~km} \mathrm{day}^{-1}$ and $>300 \mathrm{~km}$, we defined this as a flight segment (as opposed to non-flight segments). For the non-flight segments, their duration and home range (based on minimum convex polygons, Mohr 1947) were used to define characteristics of sedentary (stopover/wintering/summering) segments. Breeding sites were defined as the last "stopover sites" occupied before end of June, where birds stayed within a radius of $30 \mathrm{~km}$ for between 7 and 26 days (Kölzsch et al. 2015), while the molting sites were defined as the stopover sites where birds stayed from early July to middle August, within a radius less than $5 \mathrm{~km}$. Finally, we grouped all remaining adjacent non-sedentary segments as migration segments (Wang et al. 2018).

We defined departure date as the date of the first position when a bird left wintering/molting/breeding sites and was judged by the methods above to have acquired flight status. Arrival date was defined as the date when a bird was determined to have arrived at wintering or breeding sites, based on the methods above to qualify as "non-flight" status after a period of flight. The duration of migration was calculated as the time a bird took to travel (including stopovers) between the last summering site and first wintering site (autumn migration) or between the last wintering and the first summering site (spring migration). Sites where birds rested and fed during migration for more than 2 days were considered stopover sites (Kölzsch et al. 2016), and the number of stopovers was calculated accordingly. Stopover duration was the sum of all days spent at all stopover sites during each migration season. Thus, the days actually spent travelling (total travel days) were calculated as total migration duration minus stopover duration. We defined flight leg as the journey connecting subsequent stopover, wintering or breeding sites, to generate the number of flight legs involved during each spring/autumn migration. We defined migration distance as the cumulative travel distance between all adjacent GPS locations which were defined as "flight" status during migration, the distance between two adjacent GPS locations. Step length was calculated as the migration distance divided by the number of flight legs during each migration season. We calculated the path tortuosity of the flight between breeding and wintering areas in both directions using the straightness index of Benhamou (2004). Based on the above results, we were able to calculate migration speed as migration distance divided by migration duration, and the travel speed was calculated by dividing migration distance by total travel days.

We used linear mixed models to compare migration duration, migration speed, migration distance, 
straightness index, total travel days, travel speed, number of stopovers, stopover duration and step length of spring and autumn migration, using these measures as fixed factors, with "bird ID", "logger type" and "migration year" as random variables. Models were fitted using nlme package (Bates and Pinheiro 1998) in R (R Development Core Team 2017). All estimates presented in tables and text were based on these estimated mean $\pm \mathrm{SE}$, unless otherwise stated.

\section{Results}

Data from the full spring migration routes (Fig. 1a) showed that the Greater White-fronted Geese $(n=11)$ wintered mainly in the middle and lower Yangtze River, most of them wintering in Poyang Lake $(n=8)$. Some birds changed wintering sites during the subsequent wintering period from Shengjin Lake to Poyang Lake $(n=2)$ and Dongting Lake to Poyang Lake $(n=1)$. After leaving wintering areas, they travelled $\sim 5000 \mathrm{~km}$ to their breeding areas either in the Lena Delta $(n=7)$ or the southern tundra zone of Proliv Dmitriya Lapteva $(n=4$, Figs. 1a, 2). Most stopover sites were in Northeast China on both migration episodes (Fig. 1a, b). Most birds left wintering areas in late March, arrived at breeding/summering areas in early June, started autumn migration in late September, and returned to wintering areas in late October (Table 2 and see Additional file 1: Table S1 for full details of stopover sites).

The duration of migration was significantly longer $\left(t_{18}=9.7, \quad p<0.001\right.$; Fig. 3a $)$ in spring (mean $=79 \pm 12$ days, range $=64-97$ days, $n=11$ ) than autumn ( $35 \pm 7$ days, range $=20-43$ days, $n=9$ ). However, the distances the tagged birds travelled during spring migration and autumn did not differ significantly $\left(t_{16}=2.0, p=0.062\right.$; Fig. 3b, spring: $6111 \pm 477 \mathrm{~km}$, range $=5457-7295 \mathrm{~km}, n=11$; autumn: $5733 \pm 363 \mathrm{~km}$, range $=5155-6146 \mathrm{~km}, n=9$ ). The straightness indices of both migration seasons were almost the

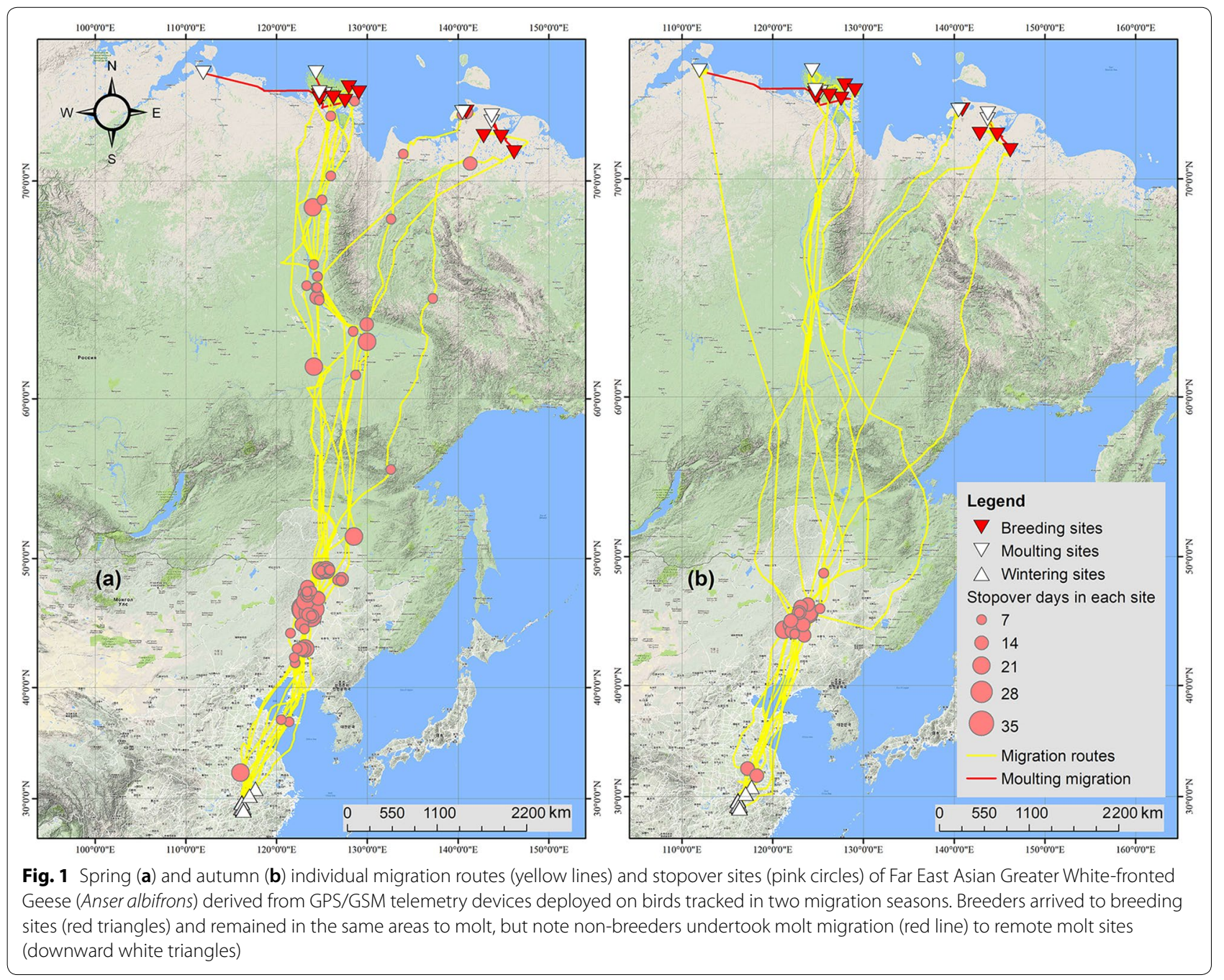




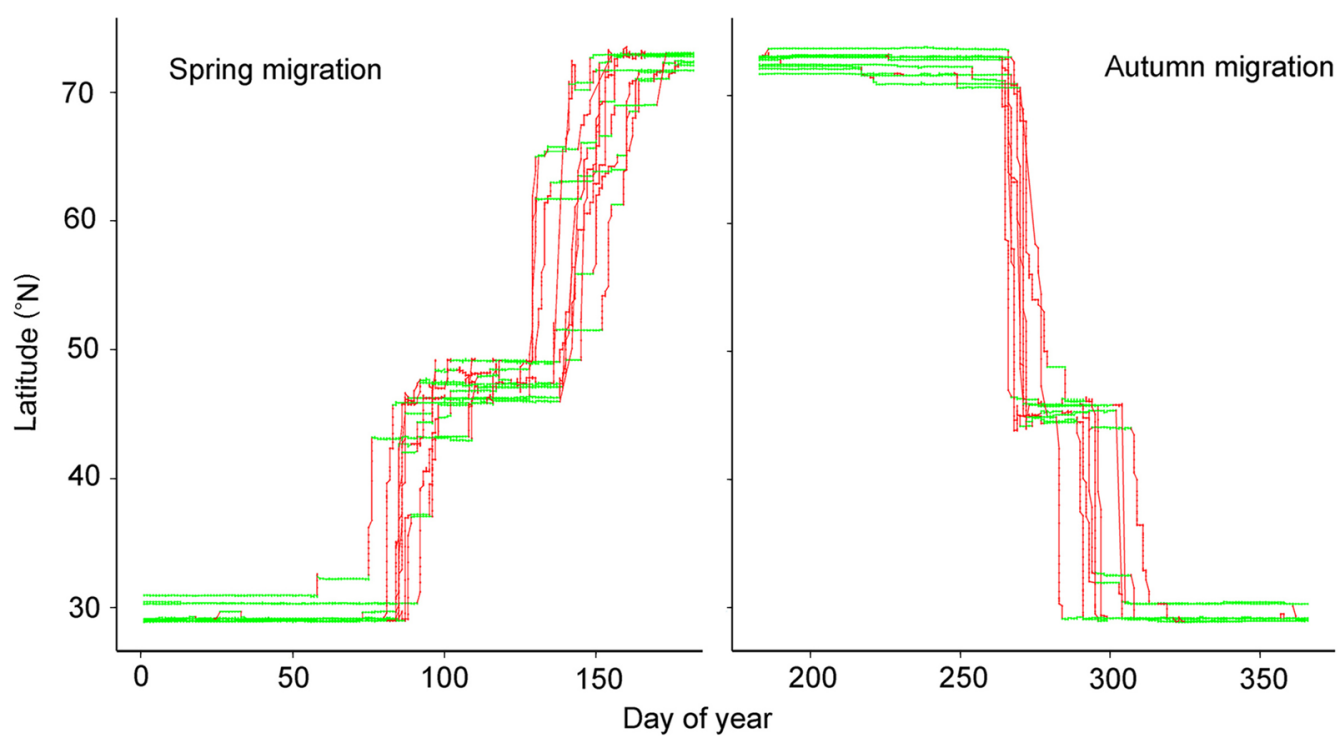

Fig. 2 Spring (left) and autumn (right) migration of Far East Asian Greater White-fronted Geese (Anser albifrons) derived from GPS/GSM telemetry devices deployed on birds tracked in two migration seasons plotting positional latitude against date. Green lines indicate non-flight segments (i.e. sedentary at staging/wintering/summering areas) and red lines indicate flight segments (i.e. migration episodes for each individual)

Table 2 Summary table comparing the mean values of autumn and spring migration parameters generated from tagged Greater White-fronted Geese (Anser albifrons) fitted with solar-powered GPS/GSM telemetry devices in China 2014-2016, which provided full information on at least one complete spring and autumn migration used in the current analysis

\begin{tabular}{lcc}
\hline Measures & Spring (mean $\mathbf{S D}$ ) & Autumn (mean \pm SD) \\
\hline $\begin{array}{l}\text { Departure date (Julian } \\
\text { date) }\end{array}$ & $83 \pm 9$ & $264 \pm 4$ \\
Arrival date (Julian date) & $162 \pm 10$ & $300 \pm 9$ \\
Migration duration (days) & $79 \pm 12$ & $35 \pm 7$ \\
Migration distance (km) & $6111 \pm 477$ & $5733 \pm 363$ \\
Migration speed (km/ & $79 \pm 16$ & $170 \pm 46$ \\
$\quad$ day) & & \\
Total travel days (days) & $20 \pm 5$ & $12 \pm 4$ \\
Travel speed (km/day) & $327 \pm 93$ & $2.1 \pm 0.8$ \\
Number of stopovers & $6.1 \pm 1.9$ & $3.1 \pm 0.8$ \\
Number of flight Legs & $7.1 \pm 1.9$ & $23 \pm 6$ \\
Stopover duration (days) & $59 \pm 16$ & $1710 \pm 476$ \\
Step length (km) & $787 \pm 302$ & $0.86 \pm 0.06$ \\
Straightness index & $0.81 \pm 0.06$ &
\end{tabular}

identical $\left(t_{17}=-1.9, p=0.072\right.$, spring: $0.81 \pm 0.06$, range $=0.66-0.89, \quad n=11 ; \quad$ autumn: $0.86 \pm 0.06$, range $=0.80-0.95, n=9)$ and close to the shortest distance which is the displacement of the initial and final points during one migration trip between wintering and breeding sites. Travel speed differed significantly between the two seasons $\left(t_{9}=-3.9, p=0.003\right.$; Fig. 3c, spring: mean $=327.0 \pm 93.2 \mathrm{~km} /$ day, range $=198.6-$ $512.0 \mathrm{~km} /$ day, $n=11$; autumn: $526.1 \pm 155.4 \mathrm{~km} /$ day, range $=296.4-819.3 \mathrm{~km} /$ day, $n=9$ ). Total travel days also differed significantly $\left(t_{8}=5.0, p=0.001\right.$; Fig. $3 \mathrm{~d}$, spring: mean $=20.03 \pm 5.45$ days, range $=12.25$ 29.25 days, $n=11$; autumn: mean $=11.87 \pm 3.91$ days, range $=6.29-18.71$ days, $n=9$ ). The major difference in migration duration was the result of significantly longer cumulative stopover duration $\left(t_{16}=6.5, \quad p<0.001\right.$; Fig. 3e, spring: $59 \pm 16$ days, range $=40-84$ days, $n=11$; autumn: $23 \pm 6$ days, range $=10-28.79$ days, $n=9)$. Geese used significantly more stopovers in spring (mean $=6.1 \pm 1.9$, range $=2-9, n=11$ ) than in autumn (mean $=2.1 \pm 0.8$, range $=1-3, n=9 ; t_{17}=5.9$, $p<0.001$; Fig. 3f). Full details of the locations and duration of stopovers used by tagged individuals are provided in Additional file 1: Table S1.

\section{Discussion}

Our results show that the time taken for Greater Whitefronted Geese to migrate between breeding sites in Far Eastern Arctic Russia and their wintering sites in the Yangtze River Floodplain in China in the autumn was less than half the time needed to cover the same distance during spring migration. Similar results were reported for a different population of the same species in Europe (Kölzsch et al. 2016). Although we should be prudent about interpreting results from relatively few individuals, these findings generally contradict empirical findings 

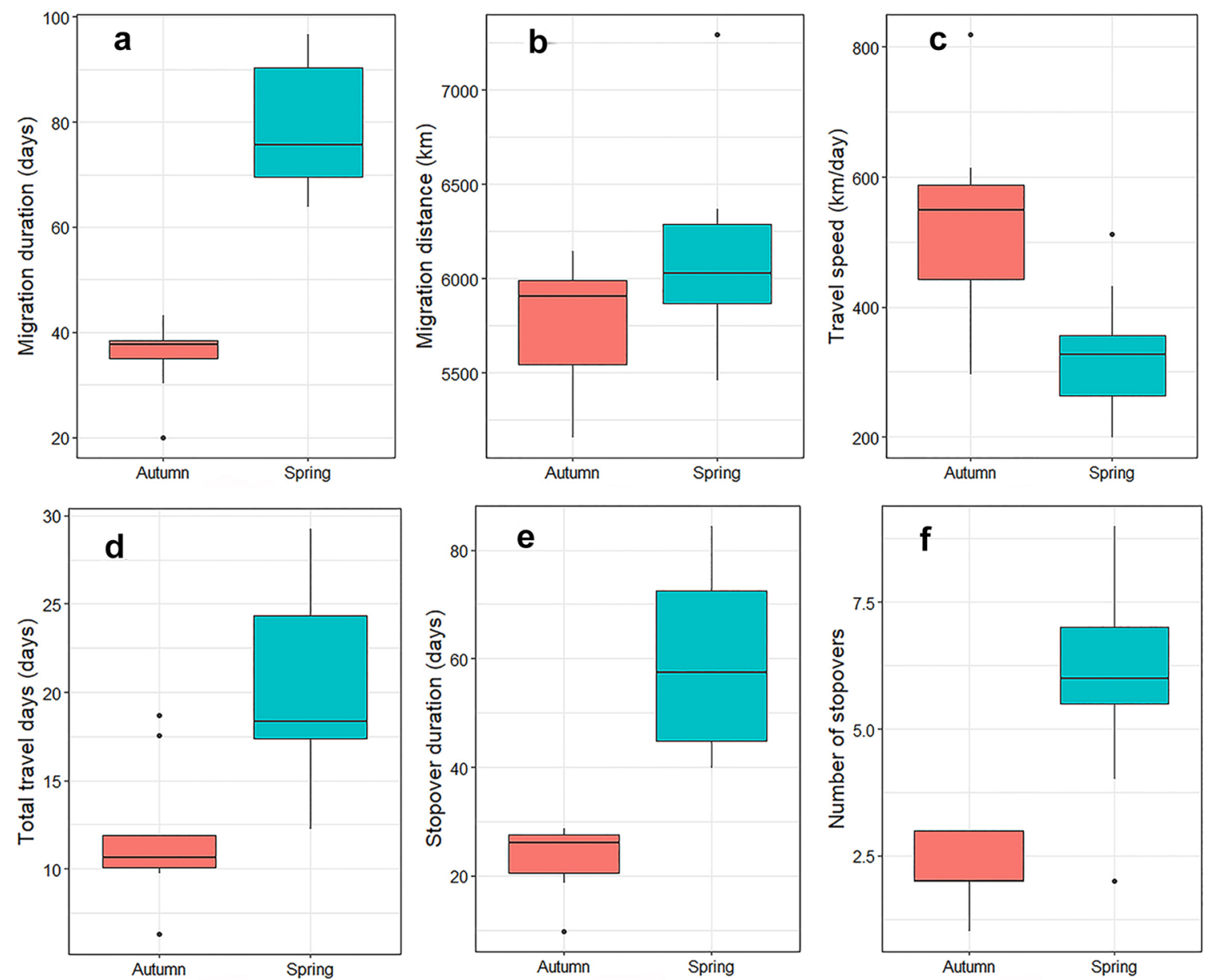

Fig. 3 Box plots (with outliers) comparing some of the key migration properties of Tar Eastern Greater White-fronted Goose (Anser albifrons) migration episodes during spring (blue-green) and autumn (red): a migration duration (days), b migration distance (km), c travel speed (km/day), $\mathbf{d}$ total travel days (days), e stopover duration (days) and $\mathbf{f}$ number of stopovers ( $n$ )

(Nilsson et al. 2013) that show that most migratory birds (mostly songbirds and shorebirds, but including ducks, swans and geese in that study) travel faster in spring than autumn because long-distance migrants are more timelimited during spring migration. Theory predicts that competition for best breeding sites might be the dominant driver for arrival earliest at limited breeding sites (Kokko 1999), which suggests that migrants should adopt the time minimization strategy during spring migration in order to arrive as early as possible in the best possible condition at breeding sites.

As well as demonstrating the more rapid return in autumn than in spring, our data confirm that this is the result of undertaking more stopovers for longer periods in spring (especially at sites close to ultimate breeding areas) compared to autumn (when geese tend to make one long flight leg from breeding areas to Chinese staging areas, see Fig. 2). Temporal patterns of spring thaw in the Arctic can be highly variable and unpredictable
(Davies and Cooke 1983), especially to geese making long uninterrupted migration flights from further south (as in the case of Far East Asian Greater White-fronted Geese, Wang et al. 2018, and Barnacle Geese, Kölzsch et al. 2015). Amongst Arctic-nesting goose species crossing major ecological barriers in spring (e.g. unsuitable foraging habitat such as the closed taiga forest and open ocean), studies show no correlation between meteorological or snow cover conditions at sequential staging areas and those further north or at the breeding grounds (e.g. Davies and Cooke 1983; Fox et al. 2014). Hence, these geese must undertake prolonged leaps across such barriers on spring migration to arrive at subsequent spring staging and ultimate nesting areas without prior knowledge of conditions prevailing there. In contrast, NW European Greater White-fronted Geese undertook relative short flights between frequent stopover in spring, where they are more able to predict conditions at further spring areas "upstream" (Kölzsch et al. 2016). Goose 
populations crossing major migratory barriers (such as the ocean or taiga) depart final staging sites without prior knowledge of conditions beyond. They potentially arrive to frozen substrates and deep snow cover in spring, which deny arriving geese of access to subterranean overwintering storage organs of plants as well as the benefit of growth from above ground primary production (e.g. Fox et al. 2006). Timing of egg laying among many Arctic nesting geese therefore varies greatly from year to year, mainly because of annual variation in snowmelt at such refueling area close to ultimate breeding grounds (e.g. Abraham 1980; Davies and Cooke 1983). Hence, our observations may simply reflect an atypically late spring thaw that delayed breeding birds arriving to nesting areas. However, our observations spanned three spring seasons when tagged geese arrived in areas where surface temperatures exceeded $0{ }^{\circ} \mathrm{C}$ on 28 May 2015, 29 May 2016 and 7 June 2017 (using the methods of Kemp et al. 2012) and hence experienced contrasting spring melt conditions, especially in the last year, so this interpretation is unlikely to hold.

Rather, we consider that the difference between spring and autumn is related to the reduced pace of spring migration, caused by prolonged stopovers, especially in the later stages. This difference is caused by the needs of the females to acquire energy and nutrient stores for both onwards migration as well as ultimate investment in reproduction (i.e. for egg-laying and self-maintenance during incubation) on the nesting grounds (e.g. Prop et al. 2003). Because laying females of some large avian species breeding in cold regions require stores of energy and nutrients acquired well ahead of nesting for such investment, some species deposit sufficient body stores that they can fast completely during egg-formation, e.g. Adelie Penguin (Pygoscelis adelie, Johnson and West 1973), and incubation, e.g. Common Eider (Somateria mollissima, Meijer and Drent 1999). Empirical studies show most geese that breed in the Arctic are mixed capital/income breeders, combining exogenously derived nutrient and energy with stores to lay eggs and incubate these with minimal recesses by the female to recoup depleted stores (e.g. Gauthier et al. 2003; Klaassen et al. 2006). Nevertheless, substantial body stores are often needed to meet investment needs in a clutch as well as self-maintenance of the female during her subsequent incubation, although the degree to which females acquire stores close to, or at, the breeding areas can vary enormously within populations (e.g. Schmutz et al. 2006; Klaassen et al. 2017). Clearly, there is considerable fitness value in acquiring such stores despite the apparent costs of transporting such added body mass to ultimate breeding areas (Klaassen et al. 2017). One obvious mechanism for females to minimize the cost of transporting stores through spring migration, while maximizing those on arrival, is to sequentially stage for longer periods at stopover sites closest to breeding areas, which is what we observed in our study. The Chinese wintering Greater White-fronted Geese moved first to Northeast China where they remained at stopover sites for prolonged periods, presumably to acquire stores to support the long migration episodes required to clear the taiga forest zone that several studied large-bodied waterbirds cover without stopping (Wang et al. 2018). This strategy leads to greater investment in store acquisition in the later stages (after having migrated non-stop over the taiga forest), with longer staging at near-breeding areas. Greater White-fronted Geese breeding in Alaska seem to invest little of their endogenous stores in eggs after also staging close to or on their breeding areas (Hupp et al. 2018). Despite the need for such stores, the ability of females to acquire them is likely to be a trade-off with the extent of the spring thaw at any one point in time and space (e.g. Polakowski et al. 2018). The closer females approach ultimate breeding areas, the more able they are to make decisions about their own body condition, local feeding conditions (Polakowski and Kasprzykowski 2016) and the likely feeding opportunities further upstream along the flyway towards their ultimate goal in order to decide whether to migrate further or not (e.g. Tombre et al. 2008; Kölzsch et al. 2015). Under the Green Wave Hypothesis (Drent et al. 1978; Van Der Graaf et al. 2006), female geese are assumed to follow the release of vegetation by the spring thaw, but this may be rendered unavailable depending on the state of the thaw, which can vary with meteorological conditions from year to year (e.g. Nuijten et al. 2014).

Although our arguments for such spring staging patterns above relate to breeding females, it is important to remember that adult geese tend to pair for life (Black et al. 1996) and paired male Greater White-fronted Geese play a protective role in close association with their females during the prelude to nesting (Fox and Madsen 1981). In addition, many first-winter Greater Whitefronted Geese remain with parents during spring migration, which continue to nesting areas (Fox et al. 1995, 2002). Hence, the continental movements of adult males and first spring geese will reflect those of their females and mothers respectively.

In contrast, after molting in the autumn, geese can feed on the abundant plant production of the brief Arctic summer and presumably can accumulate energy store payloads limited only by their capacity to bear them in flight, balanced against maneuverability to avoid predation. The tracking results showed all individuals departed from the breeding/molting sites to migrate non-stop to Northeast China staging areas, saving considerable time in contrast 
to prolonged use of multiple stopovers in spring along the same route. By comparison therefore, the entire northern two-thirds of the migration corridor was completed in the autumn more rapidly than in spring.

Although both Far East Asian and western European Greater White-fronted Geese completed autumn migration in less than half the time taken in spring, the two populations were exposed to contrasting circumstances during migration. Western geese exploit, to a large degree, agricultural subsidies (Fox and Abraham 2017) in winter and on spring migration deep into Russia, but are exposed to no major ecological barriers along their spring corridor (Kölzsch et al. 2016). In contrast, Chinese geese are more constrained to feed in natural habitats in winter (Yu et al. 2017) and during spring staging in Northeast China (Yu et al. 2017; Si et al. 2018), prior to traversing the ecological barrier of the taiga forest before arrival at ultimate staging areas (Wang et al. 2018). This rather suggests that western geese have the flexibility to exploit extensive areas of agricultural habitats along their migration routes and adjust timing to local conditions (Kölzsch et al. 2016). In contrast, Far East Asian geese replenish their energy stores in more natural habitats within more concentrated areas of Northeast China, underlining the urgent need for site safeguard networks in this region to effectively protect the areas exploited by the geese during critical periods in spring and autumn migration periods.

\section{Conclusions}

Kölzsch et al. (2016) listed nine species where spring migration takes longer than autumn migration, but noted contrary trends between some intraspecific populations, suggesting environmental factors affect ultimate drivers of migration timing strategies. Despite different timing, distance, habitats and nature of the migration routes, our results nevertheless confirm that Greater White-fronted Geese show consistent trends at the extreme ends of Eurasian continent. This underlines the need for comparative investigations of the migratory speed and strategies adopted by other arctic and subarctic waterbird species to better investigate the causal factors behind these observed differences.

\section{Additional file}

Additional file 1: Table S1. Location, accumulative stopover days and the number of individuals used of each stopover site for tracked Greater White-fronted Geese (Anser albifrons) from 2015-2017. Figure S1. General working flow diagram of data processing and interpretation including identification of the flight segments and sedentary segments, and determination of the migration segments.

\section{Acknowledgements}

We gratefully acknowledge the contribution of the fieldwork teams (Meijuan Zhao, Qin Zhu, Junjian Zhang and Yuzhan Yang) and the catching teams for their contributions. We acknowledge the constructive suggestions of two referees and the editor, which improved on an earlier manuscript.

\section{Authors' contributions}

XD and QZ performed the experiments, analyzed the data, wrote the paper, prepared Figures and Tables. LF performed the experiments, did the fieldwork, revised the paper. ZX performed the experiments, did the fieldwork, revised the paper. XW performed the experiments, did the fieldwork, analyzed the data. HH performed the experiments, did the fieldwork, revised the paper. LC and ADF conceived and designed the experiments, contributed reagents/ materials/analysis tools. All authors read and approved the final manuscript.

\section{Funding}

Our study was supported by the National Key Research and Development Programme of China (Grant No. 2016YFC0500406), the Chinese Academy of Sciences Key Strategic Programme, Water Ecological Security Assessment, the Major Research Strategy for Middle and Lower Yangtze River (Grant No. ZDRWZS-2017-3-3), and the National Natural Science Foundation of China (Grant Nos. 31661143027, 31670424, 31700330). The funders had no role in study design, data collection and analysis, decision to publish, or preparation of the manuscript.

\section{Availability of data and materials}

The raw data for this article can be presented for review but cannot be published because waterbirds in the East Asian-Australasian Flyway are highly threatened by illegal hunting and open access of the tracking data will show the critical location and timing of stopovers, which could potentially impact upon the birds greatly in this instance.

\section{Ethical approval and consent to participate}

The following information was supplied relating to ethical approvals (i.e., approving body and any reference numbers): The Animal Ethics Committee, Research for Eco-Environmental Sciences, Chinese Academy of Sciences provided full approval for this study. Approval for capture of and deploying transmitters on migratory birds was obtained from the Jiangxi Provincial Forestry Bureau (reference number: Ganlinban 201514, and 201570 and 201647) and Anhui Provincial Forestry Bureau (reference number: 2016178), as well as the Animal Ethics Committee at the Research for Eco-Environmental Sciences, Chinese Academy of Sciences.

\section{Consent for publication \\ Not applicable.}

\section{Competing interests}

The authors declare they have no competing interests.

\section{Author details \\ ${ }^{1}$ State Key Laboratory of Urban and Regional Ecology, Research Center for Eco-Environmental Sciences, Chinese Academy of Sciences, Beijing 100085, China. ${ }^{2}$ University of Chinese Academy of Sciences, Beijing 100049, China. ${ }^{3}$ School of Life Science, University of Science and Technology of China, Hefei 230026, Anhui, People's Republic of China. ${ }^{4}$ Key Laboratory of Forestry Remote Sensing Based Big Data and Ecological Security for Hunan Province, Central South University of Forestry and Technology, Changsha 410004, China. ${ }^{5}$ Information Management and System Department, IBSS, Xi'an Jiaotong-Liv- erpool University, Suzhou 215123, China. ${ }^{6}$ Department of Bioscience, Aarhus University, Kalø, Grenåvej 14,8410 Rønde, Denmark.}

Received: 15 December 2018 Accepted: 12 May 2019

Published online: 24 May 2019

\section{References}

Abraham KF. Breeding site selection of Lesser Snow Geese. PhD Thesis. Kingston, Ontario, Canada: Queen's University. 1980. 
Barraquand F, Benhamou S. Animal movements in heterogeneous landscapes: identifying profitable places and homogeneous movement bouts. Ecology. 2008;89:3336-48

Batbayar N, Takekawa JY, Newman SH, Prosser DJ, Natsagdorj T, Xiao X. Migration strategies of Swan Geese Anser cygnoides from northeast Mongolia. Wildfowl. 2013;61:90-109.

Bates DM, Pinheiro JC. nIme: linear and nonlinear mixed effects models. R package version 3. 1998.

Benhamou S. How to reliably estimate the tortuosity of an animal's path: straightness, sinuosity, or fractal dimension? J Theor Biol. 2004;229:209-20.

Black JM, Choudhury S, Owen M. Do geese benefit from life-long monogamy? In: Black JM, editor. Partnerships in birds: the study of monogamy. Oxford: Oxford University Press; 1996. p. 91-117.

Bunnefeld N, Börger L, van Moorter B, Rolandsen CM, Dettki H, Solberg EJ, Ericsson G. A model-driven approach to quantify migration patterns: individual, regional and yearly differences. J Anim Ecol. 2011;80:466-76.

Davies JC, Cooke F. Annual nesting productivity in Snow Geese: Prairie droughts and Arctic Springs. J Wild Manage. 1983;47:291-6.

Drent R, Ebbinge B, Weijand B. Balancing the energy budgets of arctic-breeding geese throughout the annual cycle: a progress report. Verh Ornithol Ges Bayern. 1978;23:239-64.

Drent RH, Daan S. The prudent parent: energetic adjustments in avian breeding. Ardea. 1980;68:225-52.

Drent RH, Fox AD, Stahl J. Travelling to breed. J Ornithol. 2006;147(2):122-34.

Edelhoff H, Signer J, Balkenhol N. Path segmentation for beginners: an overview of current methods for detecting changes in animal movement patterns. Mov Ecol. 2016;4:21.

Ely CR, Fox AD, Alisauskas RT, Andreev A, Bromley RG, Degtyarev AG, Ebbinge B, Gurtovaya EN, Kerbes R, Kondratyev AV, et al. Circumpolar variation in morphological characteristics of Greater White-fronted Geese Anser albifrons. Bird Study. 2005;52:104-19.

Fox A, Francis IS, Bergersen E. Diet and habitat use of Svalbard Pink-footed Geese Anser brachyrhynchus during arrival and pre-breeding periods in Adventdalen. Ardea. 2006;94:691-9.

Fox AD, Abraham KF. Why geese benefit from the transition from natural vegetation to agriculture. Ambio. 2017;46:188-97.

Fox AD, Boyd H, Bromley RG. Mutual benefits of associations between breeding and non-breeding White-fronted Geese Anser albifrons. Ibis. 1995;137:151-6.

Fox AD, Hilmarsson JÓ, Einarsson Ó, Walsh AJ, Boyd H, Kristiansen JN. Staging site fidelity of Greenland White-fronted Geese Anser albifrons flavirostris in Iceland. Bird Study. 2002;49:42-9.

Fox AD, Madsen J. The pre-nesting behaviour of the Greenland White-fronted Goose. Wildfowl. 1981;32:48-54.

Fox AD, Weegman MD, Bearhop S, Hilton GM, Griffin L, Stroud DA, Walsh A. Climate change and contrasting plasticity in timing of a two-step migration episode of an Arctic-nesting avian herbivore. Curr Zool. 2014;60:233-42.

Gauthier G, Bêty J, Hobson KA. Are greater snow geese capital breeders? New evidence from a stable-isotope model. Ecology. 2003;84:3250-64.

Hijmans RJ, Williams E, Vennes C. Package "Geosphere". R package version 3. 2017.

Hübner CE, Tombre IM, Griffin LR, Loonen MJJE, Shimmings P, Jónsdóttir IS. The connectivity of spring stopover sites for geese heading to Arctic breeding grounds. Ardea. 2010;98:145-54.

Hupp J, Ward D, Soto DX, Hobson KA. Spring temperature, migration chronology, and nutrient allocation to eggs in three species of arctic-nesting geese: implications for resilience to climate warming. Global Change Biol. 2018;24:5056-71.

Jia Q, Koyama K, Choi C-Y, Kim H-J, Cao L, Gao D, Liu G, Fox AD. Population estimates and geographical distributions of swans and geese in East Asia based on counts during the non-breeding season. Bird Conserv Int. 2016;26:397-417.

Johnson SR, West GC. Fat content, fatty acid composition and estimates of energy metabolism of adélie penguins (Pygoscelis adeliae) during the early breeding season fast. Comp Biochem Phys Part B: Comp Biochem. 1973;45:709-19.

Kemp M, Emiel van Loon E, Shamoun-Baranes J, Bouten W. RNCEP: Global weather and climate data at your fingertips. Methods Ecol Evol. 2012;3:65-70.
Klaassen M, Abraham KF, Jefferies RL, Vrtista M. Factors affecting the site of investment, and the reliance on savings for Arctic breeders: the capitalincome dichotomy revisited. Ardea. 2006;94:371-84.

Klaassen M, Hahn S, Korthals H, Madsen J. Eggs brought in from afar: Svalbardbreeding pink-footed geese can fly their eggs across the Barents Sea. J Avian Biol. 2017;48:173-9.

Kokko H. Competition for early arrival in migratory birds. J Anim Ecol. 1999;68:940-50.

Kölzsch A, Bauer S, de Boer R, Griffin L, Cabot D, Exo K-M, van der Jeugd HP, Nolet BA. Forecasting spring from afar? Timing of migration and predictability of phenology along different migration routes of an avian herbivore. J Anim Ecol. 2015;84:272-83.

Kölzsch A, Müskens GJDM, Kruckenberg H, Glazov P, Weinzierl R, Nolet BA, Wikelski M. Towards a new understanding of migration timing: slower spring than autumn migration in geese reflects different decision rules for stopover use and departure. Oikos. 2016;125:1496-507.

Köppen U, Yakovlev AP, Barth R, Kaatz M, Berthold P. Seasonal migrations of four individual bar-headed geese Anser indicus from Kyrgyzstan followed by satellite telemetry. J Ornithol. 2010;151:703-12.

Lavielle M. Using penalized contrasts for the change-point problem. Signal Process. 2005;85:1501-10.

Le Corre M, Dussault C, Côté SD. Detecting changes in the annual movements of terrestrial migratory species: using the first-passage time to document the spring migration of caribou. Mov Ecol. 2014;2:19.

McNamara JM, Welham RK, Houston Al. The timing of migration within the context of an annual routine. J Avian Biol. 1998;29:416-23.

Meijer T, Drent R. Re-examination of the capital and income dichotomy in breeding birds. Ibis. 1999;141:399-414.

Mohr CO. Table of equivalent populations of North American small mammals. Am Midl Nat. 1947;37:223-49.

Moore FR, Smith RJ, Sandberg R. Stopover ecology of intercontinental migrants: en route problems and consequences for reproductive performance. In: Greenberg R, Marra PP, editors. Birds of two worlds: the ecology and evolution of migration. Baltimore: Johns Hopkins University Press; 2005. p. 251-61.

Nilsson C, Klaassen RHG, Alerstam T. Differences in speed and duration of bird migration between spring and autumn. Am Nat. 2013;181:837-45.

Nuijten RJM, Kölzsch A, van Gils JA, Hoye BJ, Oosterbeek K, de Vries PP, Klaassen M, Nolet BA. The exception to the rule: retreating ice front makes Bewick's swans Cygnus columbianus bewickii migrate slower in spring than in autumn. J Avian Biol. 2014;45:113-22.

Perrins CM. The timing of birds' breeding seasons. Ibis. 1970;112:242-55.

Polakowski M, Kasprzykowski Z. Differences in the use of foraging grounds by Greylag Goose Anser anser and White-fronted Goose Anser albifrons at a spring stopover site. Avian Biol Res. 2016;9:265-72.

Polakowski M, Kasprzykowski Z, Golawski A. Influence of temperature on the timing of spring arrival and duration of migration in Arctic goose species at a central European stopover site. Ornis Fenn. 2018;95:32-40.

Prop J, Black JM, Shimmings P. Travel schedules to the high arctic: barnacle Geese trade-off the timing of migration with accumulation of fat deposits. Oikos. 2003;103:403-14.

R Development Core Team. R: A language and environment for statistical computing. Vienna: R Foundation for Statistical Computing; 2017.

Rowe L, Ludwig D, Schluter D. Time, condition, and the seasonal decline of avian clutch size. Am Nat. 1994;143:698-722.

Schmutz JA, Hobson KA, Morse JA. An isotopic assessment of protein from diet and endogenous stores: effects on egg production and incubation behaviour of geese. Ardea. 2006;94:385-97.

Shariatinajafabadi M, Wang T, Skidmore AK, Toxopeus AG, Kölzsch A, Nolet BA, Exo K-M, Griffin L, Stahl J, Cabot D. Migratory herbivorous waterfowl track satellite-derived green wave index. PLoS ONE. 2014;9:e108331.

Si Y, Xu Y, Xu F, Li X, Zhang W, Wielstra B, Wei J, Liu G, Luo H, Takekawa J, Balachandran S, Zhang T, de Boer WF, Prins HHT, Gong P. Spring migration patterns, habitat use, and stopover site protection status for two declining waterfowl species wintering in China as revealed by satellite tracking. Ecol Evol. 2018;8:6280-9.

Sinnott RW. Virtues of the Haversine. Sky Telesc. 1984;68:158.

Tombre IM, Høgda KA, Madsen J, Griffin LR, Kuijken E, Shimmings P, Rees E, Verscheure $C$. The onset of spring and timing of migration in two arctic nesting goose populations: the pink-footed goose Anser bachyrhynchus and the barnacle goose Branta leucopsis. J Avian Biol. 2008;39:691-703. 
Van Der Graaf AJ, Stahl J, Klimowska A, Bakker JP, Drent RH. Surfing on a green wave-how plant growth drives spring migration in the Barnacle Goose Branta leucopsis. Ardea. 2006;94:567-77.

Van Noordwijk AJ, McCleery RH, Perrins CM. Selection for the timing of great tit breeding in relation to caterpillar growth and temperature. J Anim Ecol. 1995;64:451-8.

van Wijk RE, Kölzsch A, Kruckenberg H, Ebbinge BS, Müskens GJDM, Nolet BA Individually tracked geese follow peaks of temperature acceleration during spring migration. Oikos. 2012;121:655-64.

Wang X, Cao L, Bysykatova I, Xu Z, Rozenfeld S, Jeong W, Vangeluwe D, Zhao Y, Xie T, Yi K, Fox AD. The Far East taiga forest: unrecognized inhospitable terrain for migrating Arctic-nesting waterbirds? PeerJ. 2018;6:e4353.
Yu H, Wang X, Cao L, Zhang L, Jia Q, Lee H, Xu Z, Liu G, Xu W, Hu B, Fox AD. Are declining populations of wild geese in China 'prisoners' of their natural habitats? Curr Biol. 2017;27:R376-7.

Zhao M, Cong P, Barter M, Fox AD, Cao L. The changing abundance and distribution of Greater White-fronted Geese Anser albifrons in the Yangtze River floodplain: impacts of recent hydrological changes. Bird Conserv Int. 2012;22:135-43.

Zhao Q, Wang X, Cao L, Fox AD. Why Chinese wintering geese hesitate to exploit farmland. Ibis. 2018;160:703-5.
Ready to submit your research? Choose BMC and benefit from:

- fast, convenient online submission

- thorough peer review by experienced researchers in your field

- rapid publication on acceptance

- support for research data, including large and complex data types

- gold Open Access which fosters wider collaboration and increased citations

- maximum visibility for your research: over $100 \mathrm{M}$ website views per year

At BMC, research is always in progress.

Learn more biomedcentral.com/submissions 